\title{
Influence of high physical load endurance exercises on the anthropometric parameters and health status of military personnel
}

\author{
Liana Plavina, Natalija Vellere, and Silvija Umbrasko \\ Rīga Stradiņš University, Latvia
}

\begin{abstract}
Military personnel are in high-risk group for health disorders, musculoskeletal pathology and psychological overload. We provide evaluation of the anthropometric parameters and health status of military personnel, Cadets, who have participated in ten days duration Combat training course. Combat training course is associated with life-style change - social, environmental, climate and geographical conditions, biorhythms, nutrition etc., with an increase in physical and psych emotional loads. It is characterized with transition from daily routine of military study process in National Defence academy to military exercise in external environment. Cadets faced to feeding limitation, sleeping deprivation intensive and continuous training, strict discipline etc. We provided analysis of anthropometric parameters before, and in time of Combat training course, summarized data of health statement and health problems that were fixed in the medical cards. The proper body mass supports good health capacity and we provided assessment of it. Physical fitness and body composition have adverse effect on military performance. Body composition undergoes changes during higher physical load performance. Military personnel have high risk to health, concerning impact of external and internal factors. According the review of medical cards of cadets group, we indicated main problems, which are fixed after the Combat training course.
\end{abstract}

Key words: anthropometric characteristics of military personnel, musculoskeletal pathology, health disorders, and high endurance exercise effect.

\section{Introduction}

Military duties are associated with life-style change - social, environmental, climate and geographical conditions, biorhythms, nutrition etc., with increased physical and psycho emotional loads [1-3]. The next officers, cadets of National Defence Academy, have to train in special military surrounding, and be fit for any military task. High physical load is a compulsory part of military study programme. Next military officers of Land Forces, Marine and Air Forces participate in Combat training course at the beginning of summer. Combat training course is a unique military environment designed to rapidly physical, cognitive, social changes in participants [4]. Cadets had military tactical tasks with high physical load and military equipment (average moving distance about $10 \mathrm{~km}$ ), sleeping deprivation and nourishment limitation. There is no any restriction on taking drinking water. High intensity training (Combat training course) is important for self-confidence, self-assurance of military leaders. Standardized nature of stressors provides a unique opportunity to examine changes simultaneously occurring in condition of individual adaptation to a new environment. 
Before high intensity training it is important to provide preventive measures to reduce the risk of health disorders related to specific job and provide necessary medical help at early stage. Dynamic load and static load can cause overstress with high risk of health disorders, musculoskeletal pathology and psychological overload [5-10]. Physical fitness level is important for high physical load exercises. Energy expenditure during high physical load training leads to fatigue and exhaustion. The body composition and physical fitness are related to demands of military service [11]. The body mass supports good health capacity, the effects of excess body mass are widespread, raise variety of concerns relevant to the health and performance of military personnel [12-16].

Due to the high level of physical load to which participants of combat training are exposed and the specific military tasks they are required to perform, cadets run an increased risk of sustaining injuries, including overexertion injuries of the locomotor system [17, 18]. Various predisposing factors play important role as risk factors of injuries in locomotor system such as individual fitness age, gender, smoking habits, biomechanical characteristics such as the shape of the foot, spinal curvature. One of the main causes of complaints and injuries is carrying various items of equipment over long distances. The purpose of our study was to analyse anthropometric characteristics, and health problems in participants of Combat training course.

\section{Material and methods}

We provide evaluation the anthropometric characteristics of cadets, participants of the Combat training course. The cadets group includes 49 military persons of both genders (included 41 males and 8 females) of age 22-30 (average age 24.9 years). During the combat training course, cadets wore the standard equipment of soldiers that consists of a helmet carrying strap, backpack, and rifle. The weight of total equipment was over $21-23 \mathrm{~kg}$. Combat training course is mentally, emotionally and physically stressful. Cadets participate in rigorous physical and mental training, including loaded road marching, obstacle exercises, swim survival exercises, confidence exercises. Training for males and females is similar. We provide body mass registration at the beginning (the first day) at the middle (the third day) and at the end (on ninth day) of Combat training course. We evaluated the anthropometric data, and data of health statement fixed in the medical cards before and after Combat training course. We provided analysis of basic anthropometric measurements: body mass, body height. Body mass index was calculated by dividing body mass (kilograms) by the square of height (meters). We have provided the standardized Nordic Questionnaire for analysis musculoskeletal symptoms [19], and assessed data of standardized Nordic Questionnaire for Analysis Musculoskeletal Symptoms in the study group before combat training course.

\section{Results and discussion}

Respondents of study group were in aged from 23 years till 30 years (average age 24.9 years) that corresponds to early adulthood. Age distribution of participants of study group is shown in Fig. 1.

Respondents of study group participate in the Combat training course, which is a unique military environment designed to rapid physical, cognitive, social changes in participants. Experience of military service is important to executing military exercise task and selfmanagement of physical and intellectual capacities. 54.5\% of participants of examined groups were in military service for one year, $31.8 \%$ of respondents were in military service till five years, $13.6 \%$ of cadets engaged on Armed forces till ten years. 


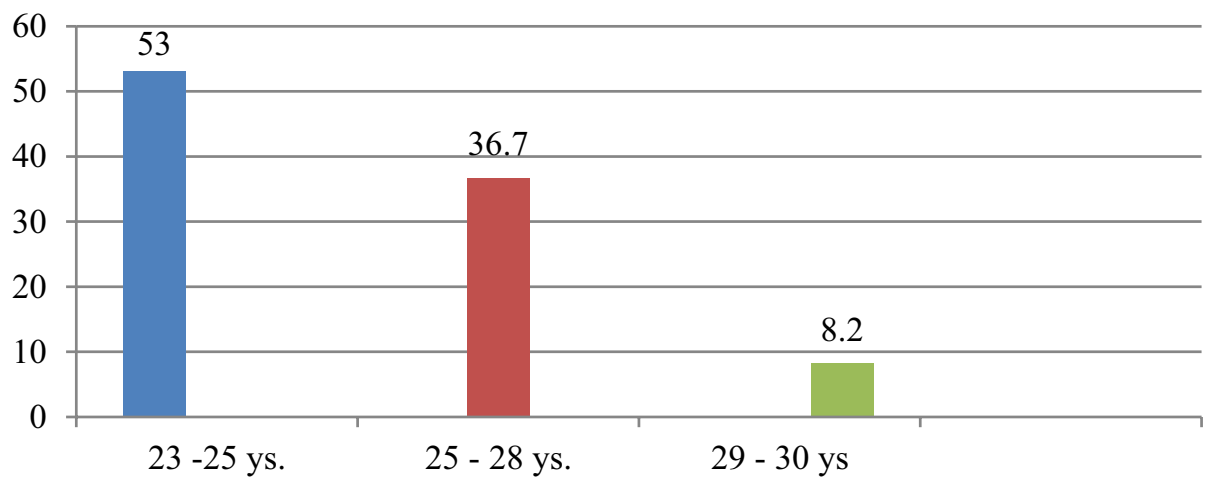

Fig. 1. Distribution of Age for cadets - participants of Combat training course.

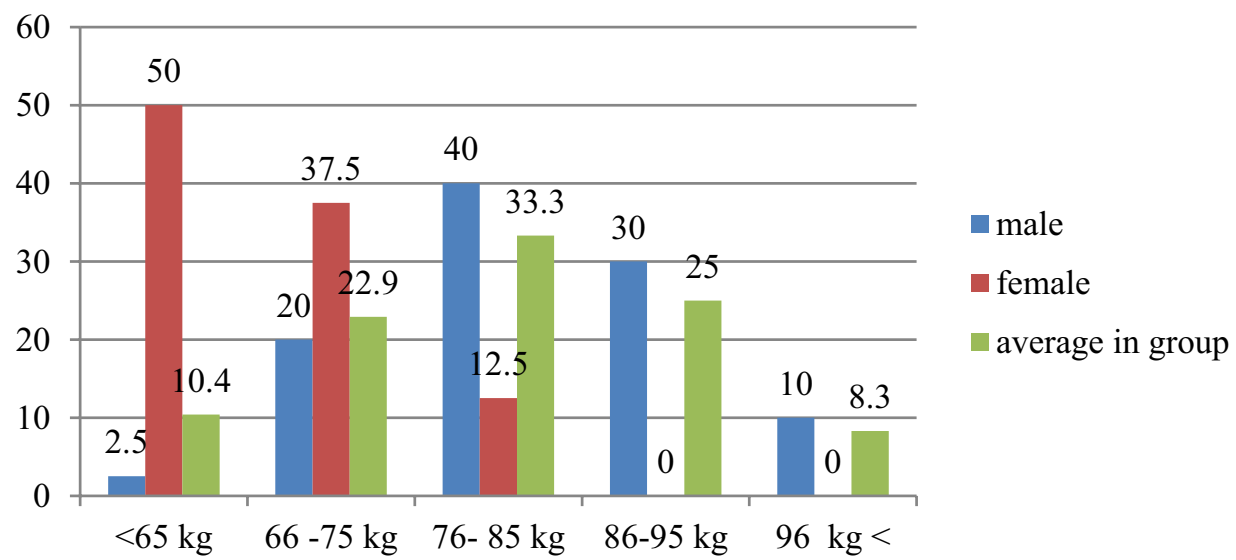

Fig. 2. Scale of variation of the body mass value for cadets according to gender in study group.

Analysis of body mass value of respondents, participants of Combat training course, reflects large scale of variation in the age period of early adulthood from 23 years till 30 years (Fig. 2). For individuals (in male group) the value of body mass varies from the minimal body mass value $54 \mathrm{~kg}$ till the maximal body mass value $-95 \mathrm{~kg}$, the mean value of body mass for males was $78.4 \pm 1.7 \mathrm{~kg}$. For an individual (in female group) the value of body mass changes from the minimal body mass value $54 \mathrm{~kg}$ till the maximal body mass value $74 \mathrm{~kg}$, the mean value of body mass for females was $62.0 \pm 2.4 \mathrm{~kg}$. The body mass value of $67.5 \%$ of respondents (in male group) was found in the interval from 76 till $95 \mathrm{~kg}$. The $87.5 \%$ respondents of female group had the body mass value in the interval from $54 \mathrm{~kg}$ to $74 \mathrm{~kg}$. We provide analysis of the anthropometric index - body mass index.

The mean value of body mass index for males was $23.8 \pm 0.3$ with variations in the interval from 20.3 to 28.5 . The mean value of body mass index for female was $21.9 \pm 0.5$ with variations in the interval from 19.8 to 23.8. Body mass index value in male group for $50 \%$ respondents corresponded to the standard body mass index value (norm) data (to 24.9). For $42.1 \%$ of the respondents, body mass index value was included into interval from 25.0 till 27.9 that indicates over weight problems. The few representatives $(7.8 \%)$ had body mass index value in the interval from 28.0 to 30.0 (Fig. 3). 


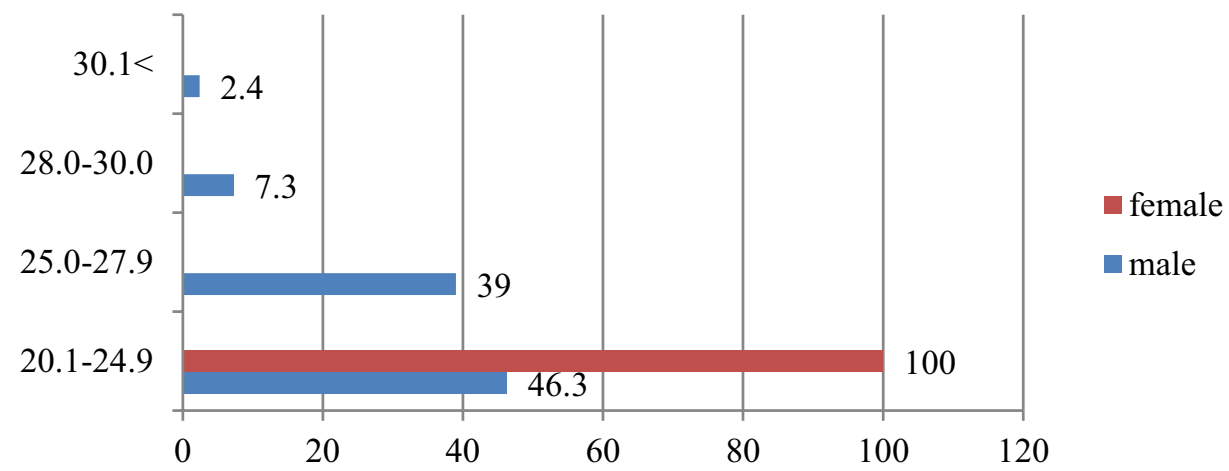

Fig. 3. Distribution of body mass index value in cadets according to gender in study group.

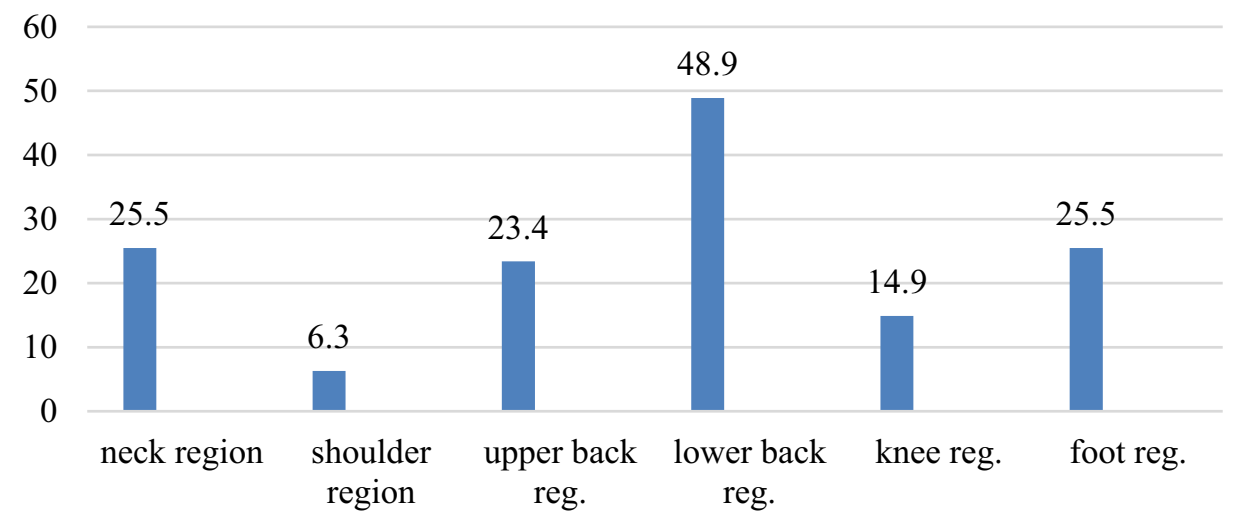

Fig. 4. Main problematic regions of loco motor system for cadets in study group according data of standardized Nordic Questionnaire for analysis musculoskeletal symptoms.

Military training is associated with an increase in physical and psycho emotional loads. Military personnel are in high-risk group for musculoskeletal pathology and physical overload. We have provided the standardized Nordic Questionnaire for analysis of musculoskeletal symptoms [19], cadets indicated main problematic regions of locomotor system, which are: the lower back (48.9\%), upper back (23.4\%), then the neck region $(25.5 \%)$ and the foot region $(25.5 \%)$. The musculoskeletal disorders (pain symptoms) in cadets are shown in Fig. 4.

Combat training course is a challenge for next military officers. During the course cadets faced with transition of daily military training routine in National Defence academy to military exercise in external environment. Such situation requires adaptation to new way of life, which includes hardship and arduous training, living in groups.

We carried out analysis of medical cards summarizing data on participants' health condition before and after the Combat training course represented. Each cadet had a special individual case history. The active participation in military training causes different surgical (orthopaedic) problems. Of the cadets, $44.9 \%$ had various traumatic injuries that were fixed in the medical cards. For $18.4 \%$ of participants of Combat training course flat foot was diagnosed (Fig. 5). 


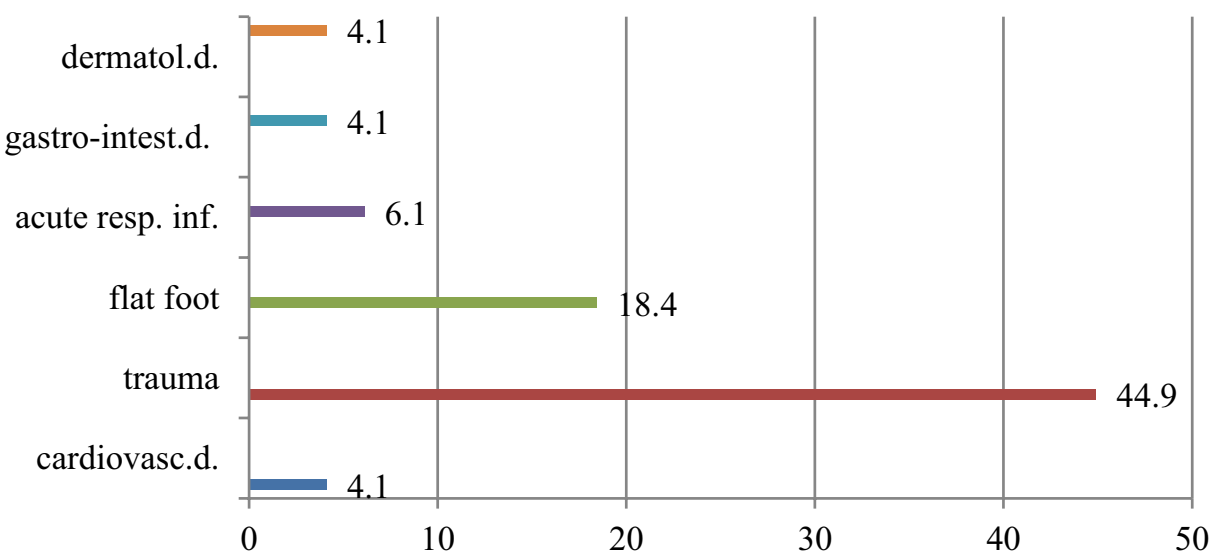

Fig. 5. The main group of health problems in cadets before Combat training course.

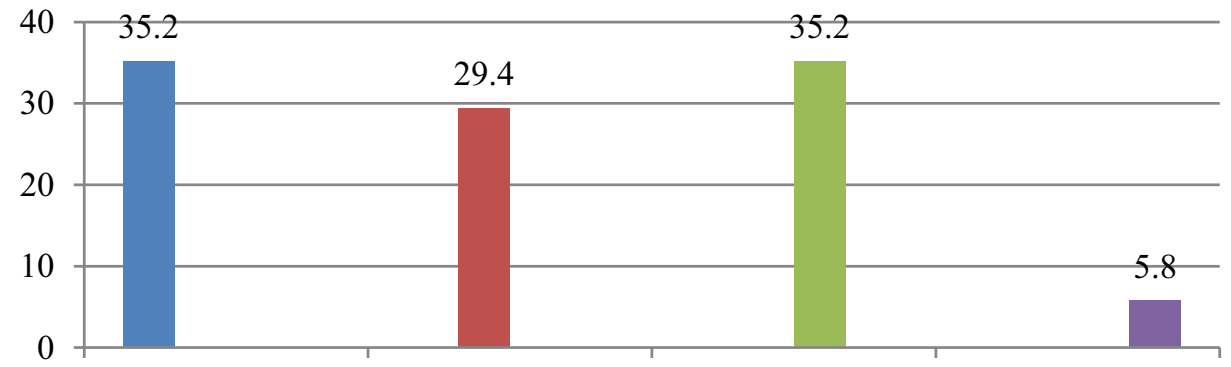

Acute respirat.d. musculo skeletal d. Dermatological d. gastrointestinal d.

Fig. 6. The main group of health problems in cadets after Combat training course.

Combat training course is a transition from daily military training routine in National Defence academy in the form of classroom training to military exercise, extremely intense and highly structured in external environment. Such situation requires adaptation to special military environment. We made analysis of health problems in participants after Combat training course (Fig. 6). The main problem of participants were acute respiratory infections (35.2\%), dermatological problems in feet were found in $35.2 \%$ of participants, and symptoms of the musculoskeletal disorders $(29.4 \%)$, the gastrointestinal problems were found in $5.8 \%$ of the study group.

The main features of Combat training course are hardship and arduous training, group living, feeding limitation, and sleeping deprivation, as well as intensive and continuous training and strict discipline. We found changes in body mass during the courses that are represented in Fig. 7.

Cadets had feeding limitation, and sleeping deprivation, intensive and continuous training. Body mass value in cadets' group decreased about two-three $\mathrm{kg}$ for half of respondents $(50.9 \%)$. Small body mass value changes (loss of body mass to one $\mathrm{kg}$ ) are fixed for $18.3 \%$ of participants on combat training course. In $12.2 \%$ of the participants changes (decreasing) of body mass value were up to six $\mathrm{kg}$. 


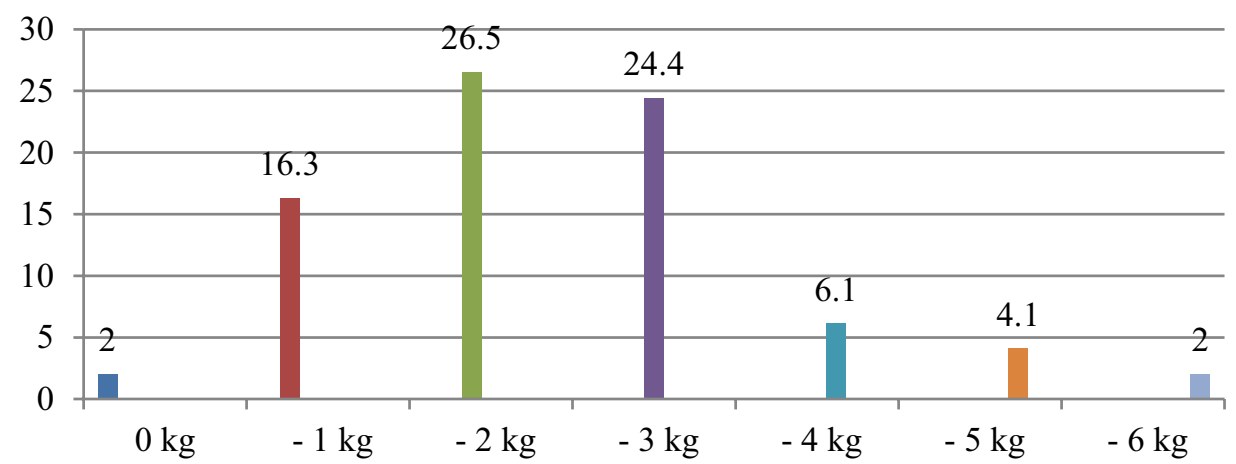

Fig. 7. Distribution of cadets concerning the Loss of Body mass $(\mathrm{kg})$ during Combat training course.

\section{Conclusions}

1. Analysis of anthropometric characteristics showed large changes of body mass and body mass index. Body mass index value for early adulthood in male group for $50 \%$ respondents and for $100 \%$ respondents in female group corresponded to the standard body mass index value data (to 24.9). For the rest part of respondents body mass index value was in the interval from 25.0 to 29.9 that indicates over weight problems.

2. According to standardized Nordic Questionnaire for analysis of musculoskeletal symptoms, cadets indicated main problematic regions, which are: the lower back (48.9\%), upper back (23.4\%), then the neck region $(25.5 \%)$ and the foot region (25.5\%). Combined musculoskeletal disorders (pain symptoms) were found in cadets.

3. Analysis of health state of participants before the Combat training course revealed large group of respondents (44.9\%) with various traumatic injuries that were fixed in the medical cards and $18.4 \%$ of participants of Combat training course had diagnosis of flat foot that can influence military training and cause injuries. Analysis of health problems for participants after Combat training course revealed such problems as acute respiratory infections $(35.2 \%)$, dermatological problems in feet (35.2\%), symptoms of the musculoskeletal disorders $(29.4 \%)$, and gastrointestinal problems $(5.8 \%)$.

4. Combat training course with transition from daily military training routine to military exercise in external environment revealed changes of body mass: Body mass value decreased about two-three $\mathrm{kg}$ for half of respondents (50.9\%). In $18.3 \%$ of participants in combat training course body mass value changes were small; they were in the interval of one $\mathrm{kg}$. There were $12.2 \%$ participants in whom changes of body mass value were about six $\mathrm{kg}$.

\section{References}

[1] S.K. Crowley, L.L. Wilkinson, L.T. Wigfall, A.M. Reynolds, S.T. Muraca, S.H. Glover, N.R. Wooten, X. Sui, M.W. Beets, J.L. Durstine, R.D. Newman-Norlund, S.D. Youngstedt, Med. Sci. Sports Exerc. 47(1), 151-158 (2015)

[2] A.E. Rodriguez-Soto, D.B. Berry, R. Jaworski, A. Jensen, C.B. Chung, B. Niederberger, A. Qadir, K.R. Kelly, S.R. Ward, Appl. Ergonomics 28(11), 1-9 (2016)

[3] P.M. Vanderburgh, Med. Sci. Sports Exerc. 40(8), 1538-45 (2008) 
[4] H.R. Lieberman, M.D. Kellogg, G.P. Bathalon, J. Am. Coll. Sports Med. 671-676 (2008)

[5] A. Aandstad, R. Hageberg, I.M. Holme, S.A. Anderssen, J. Strength Cond. Res. 28(11), 3206-14 (2014)

[6] D.B. Berry, A.E. Rodriguez-Soto, S.P. Gombatto, B. Shahidi, L. Palombo, C. Chung, A. Jensen, K.R. Kelly, S.R. Ward, J. Orthop. Res. 4, 1 (2017)

[7] M. Feuerstein, S. Berkowitz, C.A. Peck, J. Occup. Environ. Med. 39(1), 68-78 (1997)

[8] I. Mikkola, S.K. Nen-Kiukaanniemi, J.P.A. Jokelainen, P. Härknen, M. Timonen, T. Ikäheimo, Scand J. Primary Health Care 30, 95-100 (2012)

[9] R. Lystrup, F. Gordon, M. Ward, J. Hall, M. Stephens, Mil. Med. 180, 1-23 (2015)

[10] H. Taanila, J. Suni, H. Pihlajamäki, V.M. Mattila, O. Ohrankämmen, P. Vuorinen, J. Parkkari, BMC Musculoskeletal Disorders 11, 146 (2010)

[11] H. Taanila, J.H. Suni, P. Kannus, P.H. Pihlajamäki, J.P. Ruohola, J. Viskari, J. Parkkari BMC Musculoskeletal Disorders 16, 104 (2015)

[12] D. Gallagher, S.B. Heymsfield, M. Heo, S.A. Jebb, P.R. Murgatroyd, Y. Sakamoto, Am. J. Clin. Nutr. 72(3), 694-701 (2000)

[13] K.E. Friedl, J. Strength \& Conditioning Res. 26(2), 87-100 (2012)

[14] T. Heir, G. Eide, Scand. J. Med. Sci. Sports 6(4), 222-7 (1996)

[15] R. McLaughlin, G. Wittert, Obesity Rev. 10(6), 693-699 (2009)

[16] C.E. Nogueira, G.P. Guilherme, R.M. Nogueira, R. Wagner, R.M.C. Fonseca, C.C. Lunardi, J. Ricardo, J. Strength \& Conditioning Res. 30(1), 33-38 (2016)

[17] K.R. Kaufman, S. Brodine Am. J. Prev. Med. 18(3), 54-63 (2000)

[18] J.J. Knapik, K.L. Reynolds, E. Harman, Mil. Med. 169(1), 45-56 (2004)

[19] I.Kuorinka, B. Jonsson, A. Kilbom, H. Vinterberg, F. Biering-Sørensen, G. Andersson, K. Jørgensen, Appl. Ergonomics 18(3), 233-237 (1987) 